\title{
Biodiversity increases the resistance of ecosystem productivity to climate extremes
}

Forest Isbell ${ }^{1}$, Dylan Craven ${ }^{2,3}$, John Connolly ${ }^{4}$, Michel Loreau ${ }^{5}$, Bernhard Schmid ${ }^{6}$, Carl Beierkuhnlein ${ }^{7}$, T. Martijn Bezemer ${ }^{8}$, Catherine Bonin $^{9}$, Helge Bruelheide ${ }^{2,10}$, Enrica de Luca ${ }^{6}$, Anne Ebeling ${ }^{11}$, John N. Griffin ${ }^{12}$, Qinfeng Guo ${ }^{13}$, Yann Hautier ${ }^{14}$, Andy Hector ${ }^{15}$, Anke Jentsch ${ }^{16}$, Jürgen Kreyling ${ }^{17}$, Vojtěch Lanta ${ }^{18}$, Pete Manning ${ }^{19}$, Sebastian T. Meyer ${ }^{20}$, Akira S. Mori ${ }^{21}$, Shahid Naeem ${ }^{22}$, Pascal A. Niklaus ${ }^{6}$, H. Wayne Polley ${ }^{23}$, Peter B. Reich ${ }^{24,25}$, Christiane Roscher ${ }^{2,26}$, Eric W. Seabloom ${ }^{1}$, Melinda D. Smith ${ }^{27}$, Madhav P. Thakur ${ }^{2,3}$, David Tilman, ${ }^{1,28}$, Benjamin F. Tracy ${ }^{29}$, Wim H. van der Putten ${ }^{8,30}$, Jasper van Ruijven ${ }^{31}$, Alexandra Weigelt ${ }^{2,3}$, Wolfgang W. Weisser ${ }^{20}$, Brian Wilsey ${ }^{32}$ \& Nico Eisenhauer ${ }^{2,3}$

It remains unclear whether biodiversity buffers ecosystems against climate extremes, which are becoming increasingly frequent worldwide $^{1}$. Early results suggested that the ecosystem productivity of diverse grassland plant communities was more resistant, changing less during drought, and more resilient, recovering more quickly after drought, than that of depauperate communities ${ }^{2}$. However, subsequent experimental tests produced mixed results ${ }^{3-13}$. Here we use data from 46 experiments that manipulated grassland plant diversity to test whether biodiversity provides resistance during and resilience after climate events. We show that biodiversity increased ecosystem resistance for a broad range of climate events, including wet or dry, moderate or extreme, and brief or prolonged events. Across all studies and climate events, the productivity of low-diversity communities with one or two species changed by approximately $50 \%$ during climate events, whereas that of highdiversity communities with 16-32 species was more resistant, changing by only approximately $25 \%$. By a year after each climate event, ecosystem productivity had often fully recovered, or overshot, normal levels of productivity in both high- and low-diversity communities, leading to no detectable dependence of ecosystem resilience on biodiversity. Our results suggest that biodiversity mainly stabilizes ecosystem productivity, and productivitydependent ecosystem services, by increasing resistance to climate events. Anthropogenic environmental changes that drive biodiversity loss thus seem likely to decrease ecosystem stability ${ }^{14}$, and restoration of biodiversity to increase it, mainly by changing the resistance of ecosystem productivity to climate events.

Biodiversity stabilizes ecosystem productivity over time ${ }^{9,14-23}$; however, it remains unclear whether it does so by providing resistance during climate events, resilience (sensu rapid recovery ${ }^{24}$ ) after climate events, or both (Extended Data Fig. 1). Two decades ago, a seminal study reported that the ecosystem productivity of diverse grassland plant communities was more resistant and more resilient to a major drought than that of depauperate communities ${ }^{2}$. However, this study had not experimentally manipulated biodiversity, which confounded variation in biodiversity with variation in species composition and resource availability ${ }^{25}$. Hundreds of biodiversity experiments were subsequently conducted ${ }^{26,27}$, but few of these studies revisited this important question, and those that did so found mixed results ${ }^{3-13}$ Further analysis of the original data also produced mixed results ${ }^{28}$ Thus, it remains unclear whether biodiversity buffers ecosystems against climate extremes, which are becoming increasing frequent worldwide ${ }^{1}$.

We combined data from 46 experiments that manipulated grassland plant diversity and measured productivity across Europe and North America (Extended Data Fig. 2 and Extended Data Table 1). We classified each year of each experiment as extremely dry, moderately dry, normal, moderately wet, or extremely wet (Extended Data Figs 2 and 3 ) (Methods). To do this in a globally consistent manner, we used a drought index that quantified month-by-month variations in water balance over the past century on 0.5 degree $\times 0.5$ degree grids globally, based on measurements at more than 4,000 weather stations worldwide $^{29,30}$ (Extended Data Figs 2 and 3). We defined climate extremes (extremely dry or extremely wet) as events occurring less frequently than once per decade, based on the historic climate at each site over the past century (Methods). Moderately dry and wet events were defined as those that had historically occurred between once in 4 years and once per decade. Normal years included the interquartile range of observed water balances. Given these cutoffs, there were 18 extremely dry, 32 moderately dry, 87 normal, 37 moderately wet, and 21 extremely wet experiment years that occurred during these biodiversity experiments (Extended Data Figs 2 and 3). Unsurprisingly, productivity tended to be lower than normal during dry events and higher than normal during wet events (Extended Data Fig. 4), although

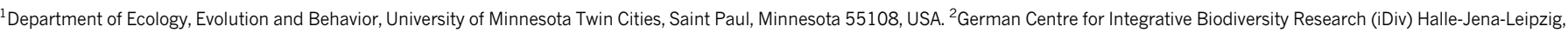

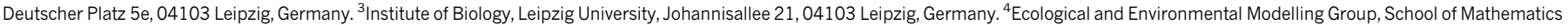

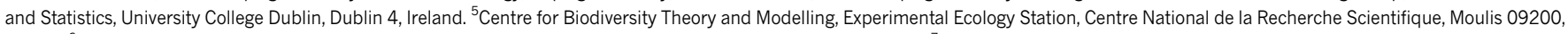

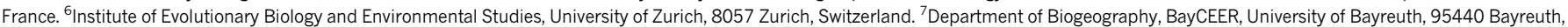
Germany. ${ }^{8}$ Department of Terrestrial Ecology, Netherlands Institute of Ecology (NIOO-KNAW), PO Box 50, 6700 AB Wageningen, The Netherlands. ${ }^{9}$ Department of Agronomy, lowa State University, Ames, lowa 50011, USA. ${ }^{10}$ Institute of Biology, Martin Luther University Halle-Wittenberg, 06108 Halle, Germany. ${ }^{11}$ Institute of Ecology, Friedrich Schiller University Jena, Dornburger Strasse 159,

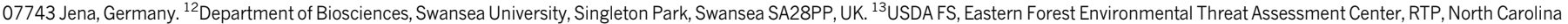

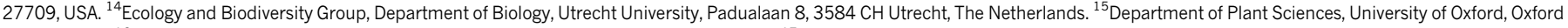
OX1 3RB, UK. ${ }^{16}$ Disturbance Ecology, BayCEER, University of Bayreuth, 95440 Bayreuth, Germany. ${ }^{17}$ Institute of Botany and Landscape Ecology, Ernst-Moritz-Arndt University Greifswald, D-17487

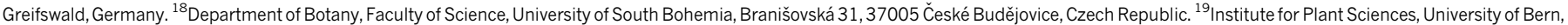

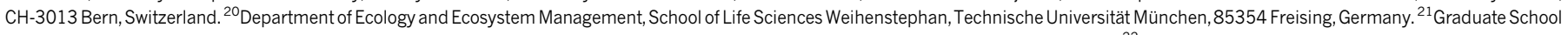

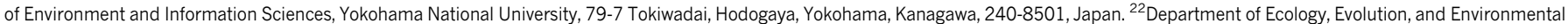

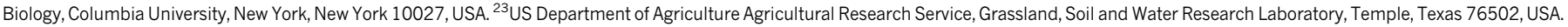

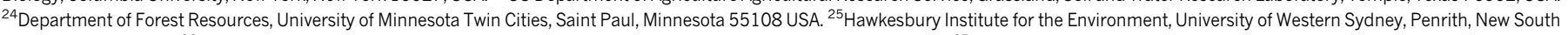

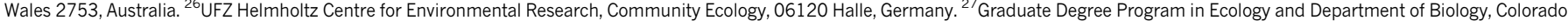

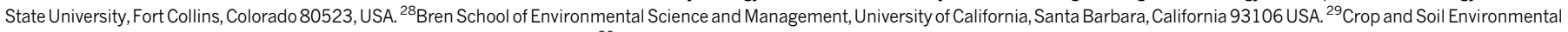
Sciences, Smyth Hall 0404, Virginia Tech, Blacksburg, Virginia 24061, USA. ${ }^{30}$ Laboratory of Nematology, Wageningen University and Research Centre, PO Box 8123,6700 ES Wageningen, The

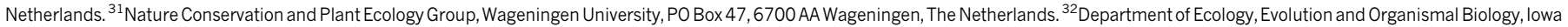
State University, Ames, lowa 50011, USA.
} 
Table 1 | Fixed effect tests and variance component estimates (standard error) for linear mixed-effects models

\begin{tabular}{lll}
\hline & \multicolumn{1}{c}{ Resistance } & \multicolumn{1}{c}{ Resilience } \\
\hline Fixed effects & & \\
$\quad$ Biodiversity & $F_{1,27.8}=20.68^{* * *}$ & $F_{1,8.5}=0.67$ \\
Direction & $F_{1,81.7}=0.53$ & $F_{1,56.9}=0.15$ \\
Intensity & $F_{1,85.6}=1.40$ & $F_{1,57.7}=2.36$ \\
$\quad$ Biodiversity $\times$ intensity & $F_{1,82.3}=3.02^{*}$ & \\
$\quad$ Biodiversity $\times$ direction & & $F_{1,46.1}=6.52^{* *}$ \\
Variance components & & \\
$\quad$ Study & $0.37(0.15)$ & $1.4 \times 10^{-6}\left(3.5 \times 10^{-8}\right)$ \\
Study $\times$ biodiversity & $0.041(0.022)$ & $0.0067(0.0096)$ \\
Study $\times$ year & $0.32(0.074)$ & $0.68(0.15)$ \\
Study $\times$ biodiversity $\times$ year & $0.033(0.011)$ & $0.018(0.012)$ \\
Plot & $0.25(0.038)$ & $9.6 \times 10^{-7}\left(2.3 \times 10^{-8}\right)$ \\
Plot $\times$ year & $2.1(0.051)$ & $4.1(0.099)$ \\
Temporal autocorrelation & & \\
$\rho_{\text {AR1 }}$ & $0.12(0.025)$ & $-0.41(0.020)$ \\
\hline$P<0.1 ; * P<0.05 ; * P<0.001$ &
\end{tabular}

$* P<0.1 ; * * P<0.05 ; * * * P<0.001$. Direction: 0 , dry; 1 , wet. Intensity: 0 , moderate; 1 , extreme. Biodiversity: $\log _{2}$ (number of species). Study $=$ factor. Year $=$ factor. Plot is defined within studies. Both response variables were $\log _{2}$-transformed. Non-significant $(P>0.1)$ interactions were excluded from the model. Kenward-Roger approximation is given for denominator degrees of freedom.

there were exceptions to this general trend (Extended Data Fig. 5). Productivity overshot normal levels when recovering during the year after extreme (but not moderate) dry and wet events (Extended Data Fig. 4), which is consistent with damped oscillations, rather than monotonic recovery, of productivity after climate extremes (Extended Data Fig. 1). Consistent with previous studies ${ }^{9,14-23}$, biodiversity increased ecosystem stability (Fig. 1a; $F_{1,37.4}=28.74, P<0.001$ ).

We quantified resistance and resilience, using proportional changes in productivity from one year to the next, within each experimental unit (plot) for each observed climate event (Methods). Linear mixedeffects models were used to test whether resistance and resilience depend on biodiversity, and how these biodiversity effects depend on climate event properties, such as the direction (wet or dry), intensity (moderate or extreme), or duration (3-24 months) of climate events, while accounting for repeated measurements (Methods).

Biodiversity increased the resistance of ecosystem productivity to a broad range of climate events (biodiversity main effect in Table 1 and Fig. 1b). That is, more diverse communities exhibited smaller proportional changes in productivity during climate events. On average, across all studies and climate events, the productivity of low-diversity communities with one or two species changed by approximately $50 \%$ ( $\Omega \approx 2$; Fig. 1 b), whereas that of high-diversity communities with $16-$ 32 species changed by approximately $25 \%(\Omega \approx 4$; Fig. $1 \mathrm{~b})$, during climate events. Biodiversity increased resistance irrespective of the direction (wet or dry) or intensity (moderate or extreme) of climate events (all interactions were non-significant, $P>0.05$; Table 1). There was, however, one marginally significant interaction: biodiversity may have increased resistance more during moderate climate events than during extreme ones (biodiversity $\times$ intensity interaction in Table 1 and Extended Data Fig. 6). There was substantial variability in the effect of biodiversity on resistance among studies and among years within studies (see variance components in Table 1, Fig. $1 \mathrm{~b}$ and Extended Data Fig. 7); however, biodiversity increased resistance similarly in long-term studies that were conducted for at least 9 years, and in short-term studies (Methods).

Examination of the dynamics of recovery shows that, at both low and high diversity, productivity had often returned to, or overshot, its normal level during the year after a climate event (Extended Data Fig. 4). Given this rapidity of recovery both for low- and for highdiversity communities, biodiversity may not have a major impact on the recovery of ecosystem productivity after climate events, at least over the timescales and climate-event intensities considered. Indeed, we were unable to detect strong and consistent effects of biodiversity on our measure of ecosystem resilience (Table 1 and Fig. 1c). Biodiversity decreased resilience after wet events, and increased, although non-significantly (see confidence intervals for 12-month events shown in Fig. 2), resilience after dry events (biodiversity $\times$ direction interaction in Table 1 and Fig. 1c). That is, less diverse communities recovered closer to normal levels of productivity during the year after wet events. On average, across all studies, climate events, and levels of biodiversity, productivity moved approximately $10 \%$ closer to normal levels $(\Delta \approx 1.1$; Fig. $1 \mathrm{c})$ during the year after climate events; however, this was often due to greatly overshooting, rather than failing to reach, normal levels of productivity (Extended Data Fig. 4). The effect of biodiversity on resilience did not vary substantially among studies or among years within studies (see relatively small point estimates with large standard errors for biodiversity variance components in Table 1 and Extended Data Fig. 8).

Next, we tested how our results depended on the duration over which climate events were defined. To do so, we considered multiple
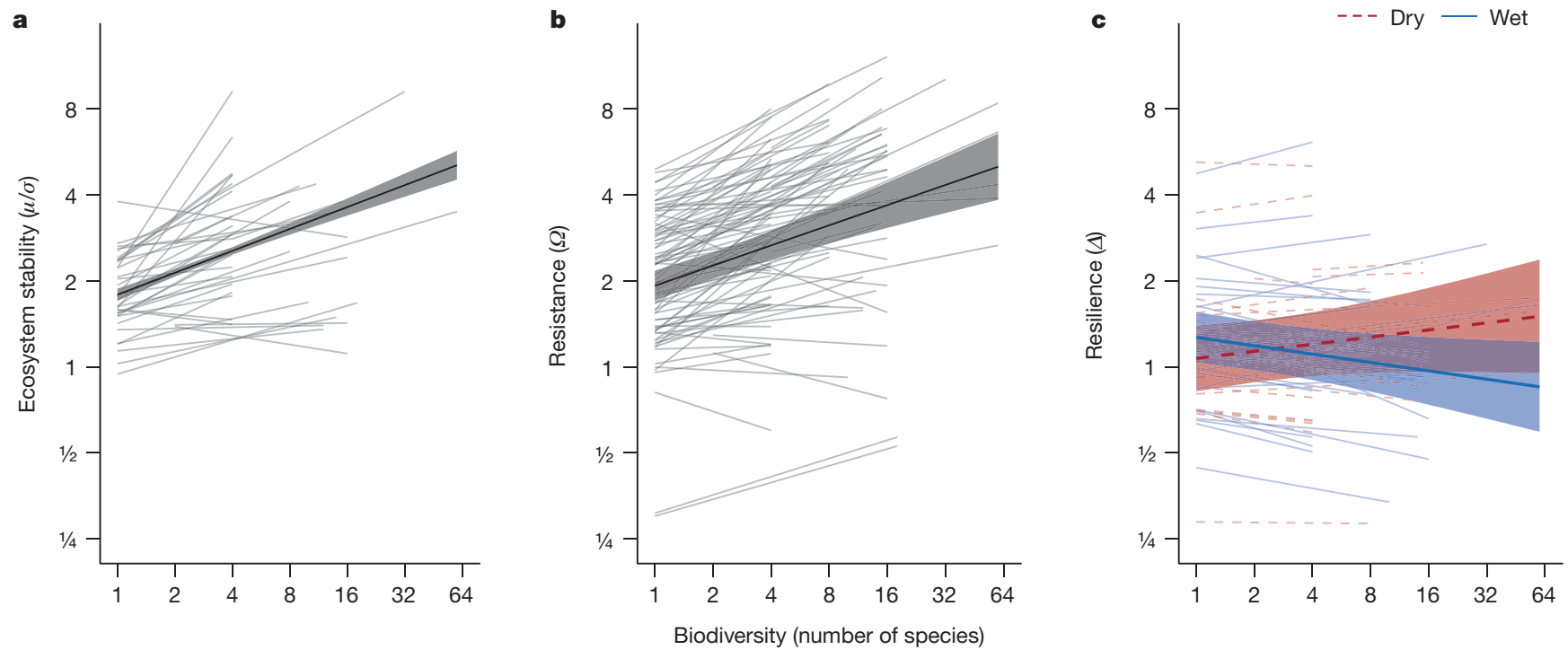

Figure 1 | Biodiversity effects on ecosystem stability, and its resistance and resilience components. Biodiversity consistently increases ecosystem stability (a) and resistance (b), but not resilience (c). Lines are mixed-effects model fits for each study (a), or each climate event within each study (b, c) (thin lines), or across climate events and studies (thick lines with bands indicating
95\% confidence intervals). Thick lines and bands in $\mathbf{c}$ indicate trends averaged across both moderate and extreme events for either dry (dashed red lines) or wet (solid blue lines) events. Stability measures are unitless. Axes are logarithmic. See Table 1 for test statistics and Extended Data Table 1 for sample sizes. 


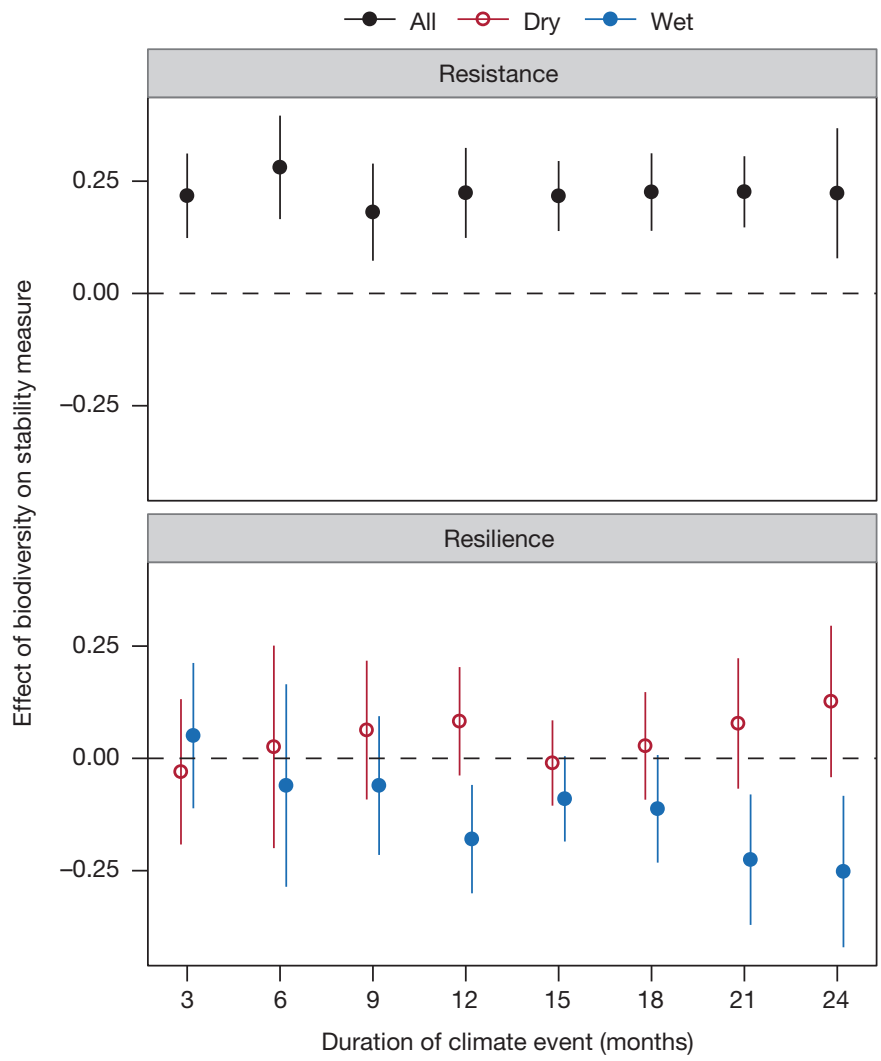

Figure $2 \mid$ Effects of biodiversity on stability measures with climate events defined over shorter or longer durations. Biodiversity consistently increases resistance; however, biodiversity effects on resilience depend on the direction (wet or dry) and duration of climate events. Values shown are parameter estimates and $95 \%$ confidence intervals for biodiversity effects from mixedeffects models, with the 12-month values corresponding to the results shown in Table 1 and Fig. 1. Values in the upper panel are averaged across both intensities and both directions. For clarity, values in the lower panel are slightly offset on the $x$ axis. See Extended Data Table 1 for sample sizes.

versions of the drought index, which aggregated water balances over different timescales, ranging from seasonal (3 months) to multi-year (24 months) events ${ }^{30}$ (Methods). We found that biodiversity consistently increased the resistance of ecosystem productivity during climate events, irrespective of the duration (3-24 months) of the climate event (Fig. 2). Biodiversity had no significant effect on the resilience of ecosystem productivity after brief, intra-annual wet or dry climate events (Fig. 2). Biodiversity decreased resilience only after prolonged, wet climate events that lasted 1 year or more (Fig. 2). The magnitudes of biodiversity effects on resistance were substantially larger than those on resilience for all but the longest durations (Fig. 2).

It is difficult, or perhaps impossible, to fully disentangle the resistance and resilience components of empirical time series, especially when there are frequent perturbations. For example, resilience to the first of two consecutive climate events could bias estimates of resistance to the second event. Similarly, resistance to the second of two consecutive climate events could bias estimates of resilience to the first event. To explore how this might have affected our results, we tested whether biodiversity effects on resistance differed between climate events that were preceded either by normal or by other climate event years, and whether biodiversity effects on resilience differed between climate events that were succeeded either by normal or by climate event years (Methods). We found that biodiversity increased resistance, especially during climate events that were preceded by climate event years (biodiversity $\times$ consecutive interaction: $F_{1,64.8}=7.21, P<0.01$ ) (Extended Data Fig. 9), and that biodiversity did not significantly impact resilience, regardless of whether a climate event was succeeded

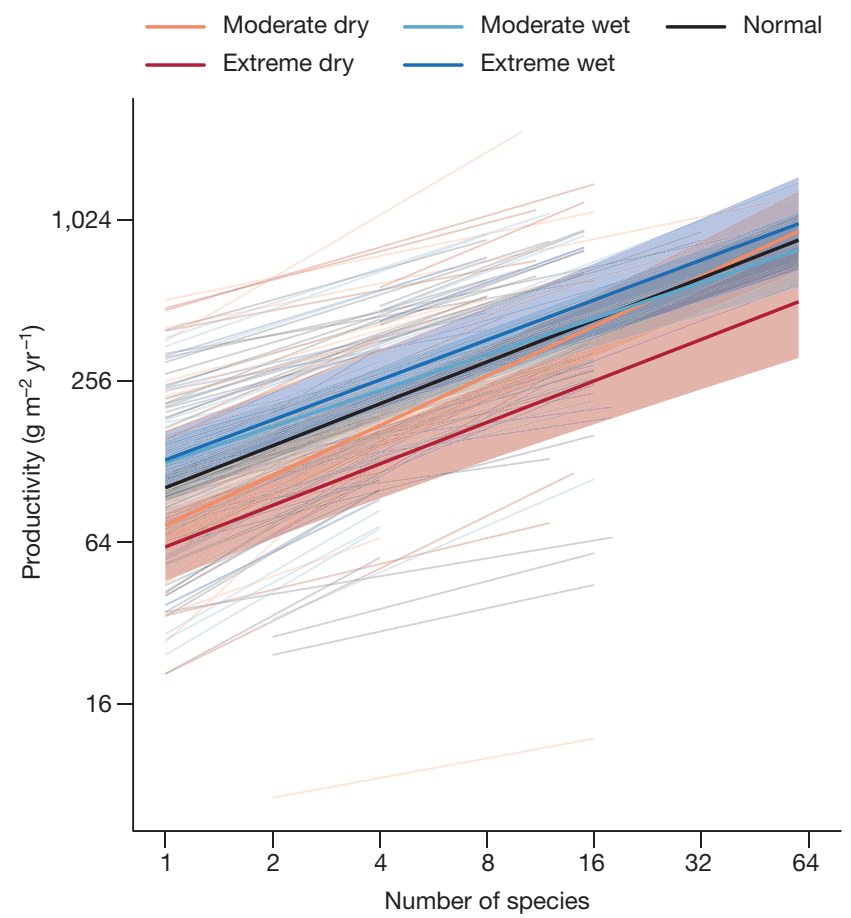

Figure $3 \mid$ Biodiversity effects on productivity during climate events or normal years. Lines are mixed-effects model fits for each year within each study (thin lines) or across all years and studies (thick lines with bands indicating 95\% confidence intervals). See Extended Data Fig. 5 for results within studies. There was a significant effect of biodiversity on productivity $\left(F_{1,30.6}=202.4, P<0.001\right)$, a significant effect of event $\left(F_{4,139.5}=6.86\right.$, $P<0.001)$, and a significant biodiversity $\times$ event interaction $\left(F_{4,124.3}=3.23\right.$, $P=0.015)$. Axes are logarithmic. See Extended Data Table 1 for sample sizes.

by a normal year or another climate event (biodiversity $\times$ consecutive interaction: $F_{1,39.6}=2.42, P=0.13$ ). We also tested whether biodiversity significantly influenced resilience when considering only climate events that were succeeded by multiple normal years in long-term studies that were conducted for at least 9 years, and with resilience quantified 2, rather than 1, years after climate events (Methods). We again found no detectable effect of biodiversity on resilience $\left(F_{1,10.6}=0.20, P=0.66\right)$. Thus, biodiversity did not influence resilience after 1 or 2 years of unperturbed recovery.

Our results suggest that greater biodiversity generally provides greater resistance. We focused on dimensionless, proportional measures of resistance and resilience to allow comparisons of communities with different levels of productivity. However, absolute measures of resistance and resilience might be of interest for some applications within particular communities, and do not necessarily depend on biodiversity in the same manner (Fig. 3 and Extended Data Figs 4 and 5). Given that biodiversity increases productivity, more productivity could be lost during dry events, and gained back after dry events, in diverse than in depauperate communities ${ }^{3,10}$. In this case, it is also important to note that our analyses show that biodiversity increased productivity not only during normal years, but also during climate events (Fig. 3).

Our results suggest that biodiversity stabilizes ecosystem productivity, and probably productivity-dependent ecosystem services, during climate events that are moderate or extreme. Anthropogenic environmental changes that drive biodiversity loss will probably decrease ecosystem stability ${ }^{14}$ by decreasing the resistance of ecosystem productivity to climate events. Restoring biodiversity will probably increase ecosystem resistance to climate extremes, which are forecast to become increasingly frequent as the global climate continues to change. 
Online Content Methods, along with any additional Extended Data display items and Source Data, are available in the online version of the paper; references unique to these sections appear only in the online paper.

\section{Received 30 April; accepted 3 August 2015.}

Published online 14 October 2015.

1. Stocker, T. F. et al. IPCC 2013: Summary for Policy Makers (Cambridge Univ. Press, 2013).

2. Tilman, D. \& Downing, J. A. Biodiversity and stability in grasslands. Nature $\mathbf{3 6 7}$ 363-365 (1994).

3. Pfisterer, A. B. \& Schmid, B. Diversity-dependent production can decrease the stability of ecosystem functioning. Nature 416, 84-86 (2002)

4. Caldeira, M. C., Hector, A., Loreau, M. \& Pereira, J. S. Species richness, temporal variability and resistance of biomass production in a Mediterranean grassland. Oikos 110, 115-123 (2005).

5. Kahmen, A., Perner, J. \& Buchmann, N. Diversity-dependent productivity in seminatural grasslands following climate perturbations. Funct. Ecol. 19, 594-601 (2005).

6. Steiner, C. F., Long, Z. T., Krumins, J. A. \& Morin, P. J. Population and community resilience in multitrophic communities. Ecology 87, 996-1007 (2006).

7. Wang, Y., Yu, S. \& Wang, J. Biomass-dependent susceptibility to drought in experimental grassland communities. Ecol. Lett. 10, 401-410 (2007).

8. Ives, A. R. \& Carpenter, S. R. Stability and diversity of ecosystems. Science 317, 58-62 (2007)

9. Griffin, J. N. et al. in Biodiversity, Ecosystem Functioning, \& Human Wellbeing: An Ecological and Economic Perspective (eds Naeem, S. et al.) Ch. 6 78-93 (Oxford Univ. Press, 2009)

10. van Ruijven, J. \& Berendse, F. Diversity enhances community recovery, but not resistance, after drought. J. Ecol. 98, 81-86 (2010).

11. Vogel, A., Scherer-Lorenzen, M. \& Weigelt, A. Grassland resistance and resilience after drought depends on management intensity and species richness. PLoS One 7, e36992 (2012)

12. Grossiord, C. et al. Tree diversity does not always improve resistance of forest ecosystems to drought. Proc. Natl Acad. Sci. USA 111, 14812-14815 (2014).

13. Wright, A. J. et al. Flooding disturbances increase resource availability and productivity but reduce stability in diverse plant communities. Nature Commun. 6 6092 (2015)

14. Hautier, Y. et al. Plant ecology. Anthropogenic environmental changes affect ecosystem stability via biodiversity. Science 348, 336-340 (2015)

15. McNaughton, S. J. Diversity and stability of ecological communities: a comment on the role of empiricism in ecology. Am. Nat. 111, 515-525 (1977)

16. Naeem, S. \& Li, S. Biodiversity enhances ecosystem reliability. Nature 390, 507-509 (1997).

17. Bai, Y., Han, X., Wu, J., Chen, Z. \& Li, L. Ecosystem stability and compensatory effects in the Inner Mongolia grassland. Nature 431, 181-184 (2004).
18. Tilman, D., Reich, P. B. \& Knops, J. M. H. Biodiversity and ecosystem stability in a decade-long grassland experiment. Nature 441, 629-632 (2006)

19. Balvanera, P. et al. Quantifying the evidence for biodiversity effects on ecosystem functioning and services. Ecol. Lett. 9, 1146-1156 (2006).

20. Hector, A. et al. General stabilizing effects of plant diversity on grassland productivity through population asynchrony and overyielding. Ecology 91 2213-2220 (2010)

21. de Mazancourt, C. et al. Predicting ecosystem stability from community composition and biodiversity. Ecol. Lett. 16, 617-625 (2013).

22. Polley, H. W., Isbell, F. I. \& Wilsey, B. J. Plant functional traits improve diversitybased predictions of temporal stability of grassland productivity. Oikos $\mathbf{1 2 2}$, 1275-1282 (2013).

23. Gross, K. et al. Species richness and the temporal stability of biomass production: a new analysis of recent biodiversity experiments. Am. Nat. 183, 1-12 (2014).

24. Pimm, S. L. The complexity and stability of ecosystems. Nature $\mathbf{3 0 7}, \mathbf{3 2 1 - 3 2 6}$ (1984).

25. Huston, M. A. Hidden treatments in ecological experiments: re-evaluating the ecosystem function of biodiversity. Oecologia 110, 449-460 (1997).

26. Cardinale, B. J. et al. The functional role of producer diversity in ecosystems. Am. J. Bot. 98, 572-592 (2011).

27. Tilman, D., Isbell, F. \& Cowles, J. M. Biodiversity and ecosystem functioning. Annu. Rev. Ecol. Evol. Syst. 45, 471-493 (2014).

28. Tilman, D. Biodiversity: population versus ecosystem stability. Ecology 77, 350-363 (1996).

29. Beguería, S., Vicente-Serrano, S. M. \& Angulo-Martinez, M. A multiscalar global drought dataset: the SPElbase: a new gridded product for the analysis of drought variability and impacts. Bull. Am. Meteorol. Soc. 91, 1351-1356 (2010).

30. Vicente-Serrano, S. M. et al. Response of vegetation to drought time-scales across global land biomes. Proc. Natl Acad. Sci. USA 110, 52-57 (2013).

Acknowledgements This paper is a product of the STABILITY group funded by sDiv, the Synthesis Centre of the German Centre for Integrative Biodiversity Research (iDiv) Halle-Jena-Leipzig (DFG FZT 118). M.L. was supported by the TULIP Laboratory of Excellence (ANR-10-LABX-41). B.S. and P.A.N. were supported by the URPP Global Change and Biodiversity of the University of Zurich.

Author Contributions F.I. and N.E. conceived the project; F.I., D.C., J.C., M.L., H.B., A.E., J.N.G., Y.H., A.H., P.M., S.T.M., A.M., K.E.M., S.N., C.R., E.S., M.P.T., J.v.R., A.W., W.W., B.W., and N.E. developed the project at a workshop; F.I. and M.L. defined dimensionless measures of resistance and resilience; F.I., D.C., J.C., B.S., C.B., M.B., C.B., H.B., E.d.L., Q.G., A.H., A.J., J.K., V.L., S.T.M., H.W.P., P.B.R., C.R., D.T., B.T., W.v.d.P., J.v.R., A.W., W.W., B.W and N.E. contributed experimental data; D.C. assembled data; F.I. analysed data, with substantial input from J.C. and B.S.; and F.I. wrote the paper, with substantial input from all authors.

Author Information Reprints and permissions information is available at www.nature.com/reprints. The authors declare no competing financial interests. Readers are welcome to comment on the online version of the paper. Correspondence and requests for materials should be addressed to F.I. (isbell@umn.edu). 


\section{METHODS}

Defining ecosystem stability measures. We define measures of resistance and resilience that are (1) dimensionless, and thus directly comparable between studies and communities with different levels of productivity; (2) symmetric, and thus directly comparable between positive and negative perturbations, such as wet and dry climate events; (3) applicable to dynamic systems that exhibit either monotonic recovery or damped oscillations after a perturbation (Extended Data Fig. 1). We define resistance as

$$
\Omega \equiv \frac{\overline{Y_{\mathrm{n}}}}{\left|Y_{\mathrm{e}}-\overline{Y_{\mathrm{n}}}\right|}
$$

and resilience as

$$
\Delta \equiv\left|\frac{Y_{\mathrm{e}}-\overline{Y_{\mathrm{n}}}}{Y_{\mathrm{e}+1}-\overline{Y_{\mathrm{n}}}}\right|
$$

where $\overline{Y_{\mathrm{n}}}, Y_{\mathrm{e}}$, and $Y_{\mathrm{e}+1}$ are respectively the expected ecosystem productivity during normal years (mean across all non-climate event years), during a climate event, and during the year after a climate event. Resistance indicates the proximity of productivity to normal levels during a climate event. For example, if productivity is reduced during a drought to half its normal level, then $\Omega=2$ (Extended Data Fig. 1). Resilience indicates the rate of return towards normal productivity levels after a climate event. If a climate event lowers productivity, greater biomass growth rates during recovery lead to greater resilience up until they are sufficiently rapid to lead to full recovery of normal levels of productivity during the subsequent year. Any biomass growth rates greater than this lead to progressively lower resilience because productivity overshoots its normal level. Thus, consistent with stability measures used in theoretical biodiversity-stability studies, this measure of resilience has a low value, indicating instability, when the deviation of the system from normal productivity levels exponentially decays at a slow rate, either via monotonic recovery or damped oscillations (Extended Data Fig. 1). For example, if during the year after a climate event productivity recovers either from 50 to $75 \%$ or from 50 to $125 \%$ of normal productivity levels, then productivity will have returned halfway from perturbed to normal levels, and $\Delta=2$ (Extended Data Fig. 1). The same is true for recovery in the opposite direction after a positive deviation: that is, recovery from 150 to $125 \%$ or from 150 to $75 \%$ of normal productivity levels would also give $\Delta=2$ (Extended Data Fig. 1). The points shown in Extended Data Fig. 1 are given by $y_{t=0}=100, y_{t=1}=100-100 / \Omega$, $y_{t=11}=100+100 / \Omega$, and, for all other $t, y_{t}=100-\left(100-y_{t-1}\right) / \Delta$ for monotonic recovery or $y_{t}=100+\left(100-y_{t-1}\right) / \Delta$ for damped oscillations, where $y$ is productivity. We use a common measure of ecosystem stability, quantified as the ratio of the mean to the standard deviation of productivity across years $(\mu / \sigma)$. This measure of ecosystem stability is dimensionless, and thus directly comparable between studies and communities with different levels of productivity.

Identifying wet and dry climate events. Drought occurs when water availability remains below normal levels over some period of time ${ }^{30}$. Identifying and quantifying droughts requires consideration of water inputs (precipitation) and water losses (potential evapotranspiration). Furthermore, doing so in a globally consistent manner requires standardization of spatially explicit historical trends for water balances, to ensure that 'normal' and 'extreme' conditions are consistently defined across sites. Finally, given that ecosystems need not similarly respond to brief or prolonged droughts, it is often useful to consider water balances aggregated over a range of short to long timescales.

We used the standardized precipitation-evapotranspiration index (SPEI) to consistently identify and quantify wet and dry climate events across field experiments over durations ranging from 3 to 24 months. SPEI is a standard normal variable for water balances aggregated over a given number of months at a particular location. SPEI values are based on month-by-month variations in climate over the past century (January 1901 to December 2011), based on monthly means of measurements made at more than 4,000 weather stations worldwide, and provided on 0.5 degree $\times 0.5$ degree grids globally. For example, a value of SPEI-12 $=-1.28$ for August 2005 at a particular location would correspond to a level of annual (as indicated by the value of 12) drought (as indicated by the negative value) that has historically occurred (between 1901 and 2011) once per decade at that location during the months of September to August (Extended Data Figs 2 and 3). Similarly, SPEI-3 $=0.67$ for August 2005 at a particular location would correspond to a level of seasonal wetness that has historically occurred once every 4 years at that particular site during the months of June to August (Extended Data Figs 2 and 3).

We extracted SPEI values from SPEIbase ${ }^{29}$ raster files for each peak biomass harvest at each study site (Extended Data Figs 2 and 3). First, we considered annual water balances: SPEI-12. Previous results suggest that primary productivity responds to approximately annual water balances in temperate grasslands ${ }^{30}$. We classified experiment years as extremely dry, moderately dry, normal, moderately wet, and extremely wet (Extended Data Figs 2 and 3). Extreme events (extremely dry or extremely wet) were defined as those that historically occurred less frequently than once per decade. Moderate events were defined as those that historically occurred between once in 4 years and once per decade. Normal years were defined as those within the interquartile range of historical water balances. Given these cutoffs, there were 18 extremely dry, 32 moderately dry, 87 normal, 37 moderately wet, and 21 extremely wet experiment years that occurred during these biodiversity experiments (Extended Data Figs 2 and 3). Thus, $20 \%$ of the experiment years $(18+21=39$ out of 195) were identified as extreme events, which corresponds to extremely dry events that occur less than once per decade (10\% of observations) plus extremely wet events that occur less than once per decade $(10 \%$ of observations). Note that there is an unavoidable shifting baseline for comparisons when defining extreme climate events. If we had defined climate extremes based only on data from the early (or late) 1900s, then we would probably have identified more (or fewer) extreme climate events.

Next, we considered how the effects of biodiversity on resistance and resilience depended on the duration over which water balances were aggregated. Specifically, we re-classified each experiment year as extremely dry, moderately dry, normal, moderately wet, and extremely wet years based on other versions of SPEI that aggregate water balances over shorter (SPEI-3, SPEI-6, SPEI-9) or longer (SPEI15, SPEI-18, SPEI-21, SPEI-24) periods of time preceding peak biomass harvests, and then re-fitted mixed-effects models.

Statistical analyses. We used linear mixed-effects models to test whether resistance and resilience depend on biodiversity, and how these biodiversity effects depend on climate event properties, such as the direction (wet or dry), intensity (moderate or extreme), or duration (3-24 months) of climate events, while accounting for repeated measurements. Models were first fitted for annual (12-month) climate events (Table 1 and Fig. 1), and then subsequently fitted for shorter or longer durations (Fig. 2). Fixed effects were included for biodiversity, quantified as the $\log _{2}$ (treatment species richness); direction, quantified as a binary variable $(0$, dry; 1 , wet); and intensity, quantified as a binary variable $(0$, moderate; 1 , extreme). All interactions were initially included, and non-significant interactions $(P>0.1)$ were subsequently excluded. Random effects were included for a study factor; a study $\times$ biodiversity interaction; a study $\times$ year interaction; a study $\times$ biodiversity $\times$ year interaction; and a plot (within-study) term. The error structure accounted for repeated measurements within experimental units (plots) across years. A first-order autoregressive covariance structure provided a better fit than a compound symmetry (split-plot-in-time) covariance structure, according to the Akaike information criterion. For all models, the response variable was $\log _{2}$ transformed to meet model assumptions.

Models were fitted with the asreml function in the asreml package in $\mathrm{R}$, and results were extracted with the test.asreml function in the pascal package (https://github.com/pascal-niklaus/pascal) in R. After model simplification, as described above on the basis of significance of fixed effects and Akaike information criterion comparisons of random effect and covariance structures, fixed effects were specified as $\sim$ biodiversity + direction + intensity + interaction (where interaction $=$ biodiversity:intensity for resistance, and interaction $=$ biodiversity: direction for resilience), random effects as $\sim$ study/(biodiversity*year) + plot, and the error structure as $\operatorname{rcov}=\sim \mathrm{id}($ plot):arl(year). These mixed-effects models were fitted for annual resistance and resilience (Fig. 1 and Extended Data Figs 7 and 8), and for all eight durations of resistance and resilience (Fig. 2). The model for productivity only differed in the specification of fixed effects, with a factor for climate event (levels of 'extreme dry', 'moderate dry', 'normal', 'moderate wet', and 'extreme wet') instead of the direction and intensity terms (Fig. 3 and Extended Data Figs 4 and 5). The biodiversity $\times$ event interaction was significant and retained in the productivity model (Fig. 3 ).

Models were fitted for resistance for all studies for which there were observations of productivity during both normal and climate event years (Extended Data Figs 3 and 7). Models for resilience were fitted for all studies for which there were observations during normal, climate event, and post-climate event years, except where the only normal year was also the only post-event year because in this case $\overline{Y_{\mathrm{n}}}=Y_{\mathrm{e}+1}$ and resilience is undefined (Extended Data Figs 3 and 8).

Species richness treatments were randomly assigned to experimental units (plots). Sample sizes were chosen within individual experiments (Extended Data Table 1) to ensure adequate power to detect an effect of richness on productivity. Testing whether biodiversity effects differed between short- and long-term studies. Given that many of these studies were conducted for only a few years, we tested whether our results differed between short- and long-term studies. We did so by adding a two-way biodiversity $\times$ study duration interaction, and a study duration main effect, to the models shown in Table 1 , where study duration was a binary variable with a value of one for the six studies conducted for at least 9 years (Extended Data Table 1), and a value of zero for all other studies. We found 
similar results between short- and long-term studies, as indicated by nonsignificant interactions between biodiversity and study duration for both resistance $\left(F_{1,16.5}=0.02, P=0.90\right)$ and resilience $\left(F_{1,23.7}=0.66, P=0.42\right)$.

Testing whether biodiversity effects differed between categorical versus continuous measures of climate event intensity. We used a categorical specification of climate intensity (moderate or extreme) throughout because there were often complex nonlinear relationships between biomass production and SPEI within sites (Extended Data Fig. 5). However, our categorical specification incurs some information loss, so we also tested whether results were similar when the models shown in Table 1 were fitted using the absolute value of the SPEI-12 index in place of the binary intensity variable. We found similar results when we considered this continuous measure of climate event intensity. That is, biodiversity increased resistance $\left(F_{1,28.0}=20.38, P<0.001\right)$ and did not affect resilience $\left(F_{1,8.5}=0.66, P=0.44\right)$

Disentangling resistance and resilience. It is difficult, or perhaps impossible, to fully disentangle the resistance and resilience components of empirical time series, especially when there are frequent perturbations. For example, resilience to the first of two consecutive climate events could bias estimates of resistance to the second event, and resistance to the second of two consecutive climate events could bias estimates of resilience to the first event. To explore how this affected our results, we added a two-way biodiversity $\times$ consecutive interaction to the models shown in Table 1, and a main effect of consecutive, where consecutive was a binary variable with a value of 1 indicating non-consecutive climate events (that is, normal year before event for resistance, normal year after event for resilience), and 0 otherwise. We also tested whether biodiversity significantly influenced resilience when considering only climate events that were succeeded by multiple normal years in long-term studies that were conducted for at least 9 years, and with resilience quantified 2, rather than 1 , years after climate events. To do so, we refitted the model shown in Table 1, but with resilience quantified using $Y_{\mathrm{e}+2}$ rather than $Y_{\mathrm{e}+1}$ in equation (2).

Robustness of results to monoculture exclusion. Given that monocultures are rare in nature, we tested whether our results depended on inclusion of monoculture plots. We found similar results when we excluded monocultures. That is, biodiversity increased resistance and did not significantly affect resilience when we refitted the models shown in Table 1 after excluding monocultures (biodiversity effect on resistance: $F_{1,20.2}=7.25, P=0.014$; biodiversity effect on resilience: $\left.F_{1,4.4}=0.21, P=0.665\right)$. 


\section{RESEARCH LETTER}

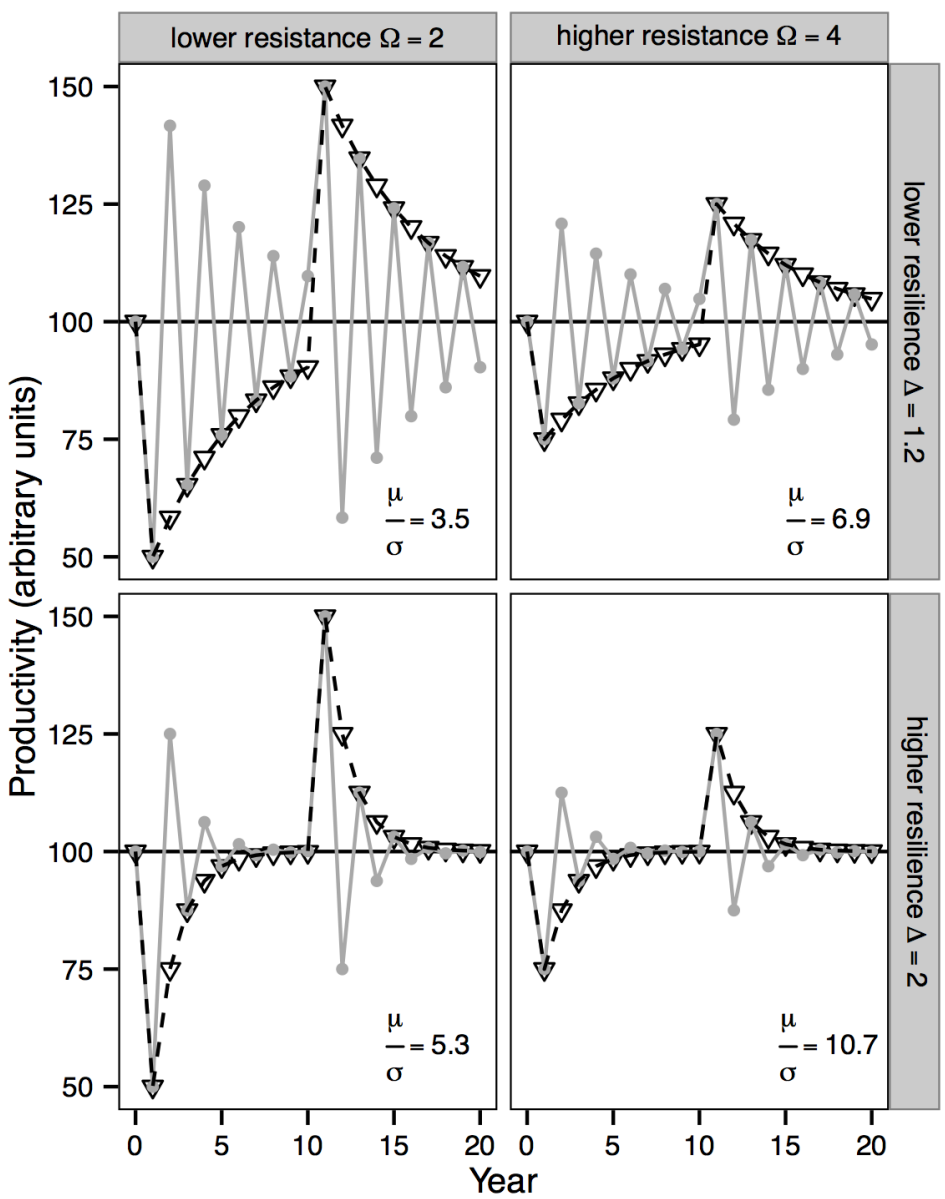

Extended Data Figure $1 \mid$ Contrasting ecosystem productivity responses to climate events for low or high levels of resistance $(\Omega)$ and resilience $(\Delta)$. In these stylized examples, productivity is decreased by a dry climate event during year one, is increased by a wet climate event during year 11, and is otherwise recovering back towards normal productivity levels either monotonically (black dashed lines and open triangles) or via damped oscillations (solid grey lines and filled circles). Ecosystem stability $(\mu / \sigma)$ depends on both resistance and resilience. See Methods for definitions of resistance and resilience. 

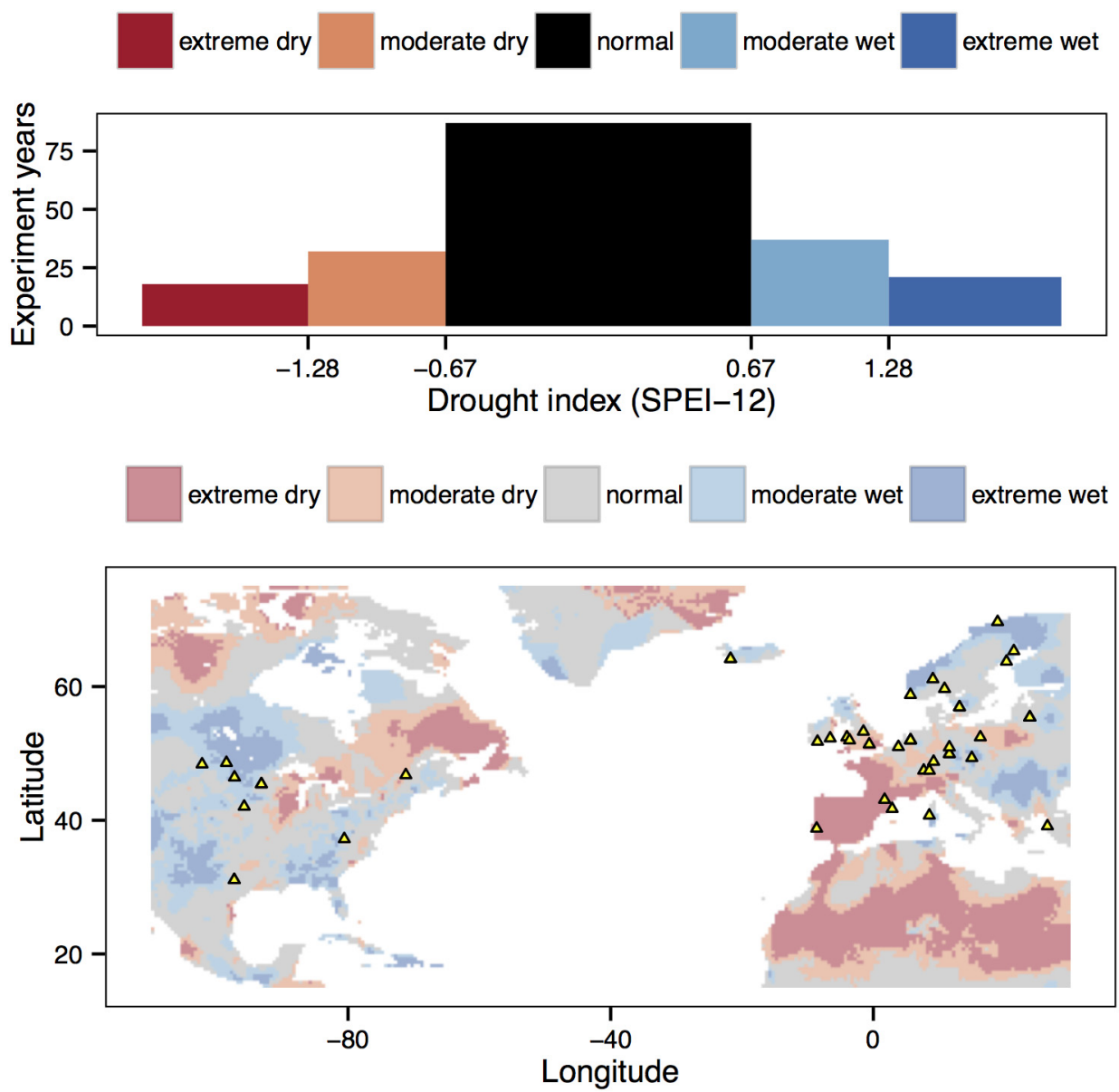

Extended Data Figure 2 Map of study site locations (bottom) and frequency of climate events (top). Bottom: locations for all 46 studies (yellow triangles) and an example of spatial variation in water balance, where SPEI-12 was classified as in the bottom panel. August 2005 was chosen for this example because many experiments were underway and harvested during this particular month of this particular year (Extended Data Table 1). The spatial patterns of wet and dry climate events shown on this map would differ at other times (that is, during a different month or year) and for climate events defined over other durations (that is, based on water balances aggregated over more or fewer than the preceding 12 months). There were multiple experiments at some sites (Extended Data Table 1), thus some symbols completely overlap on this map. Top: cutoffs for bins correspond to events occurring every 1 in 4 years $( \pm 0.67)$ or every 1 in 10 years $( \pm 1.28)$. 
- extreme dry - moderate dry $\bullet$ normal $\bullet$ moderate wet $\bullet$ extreme wet

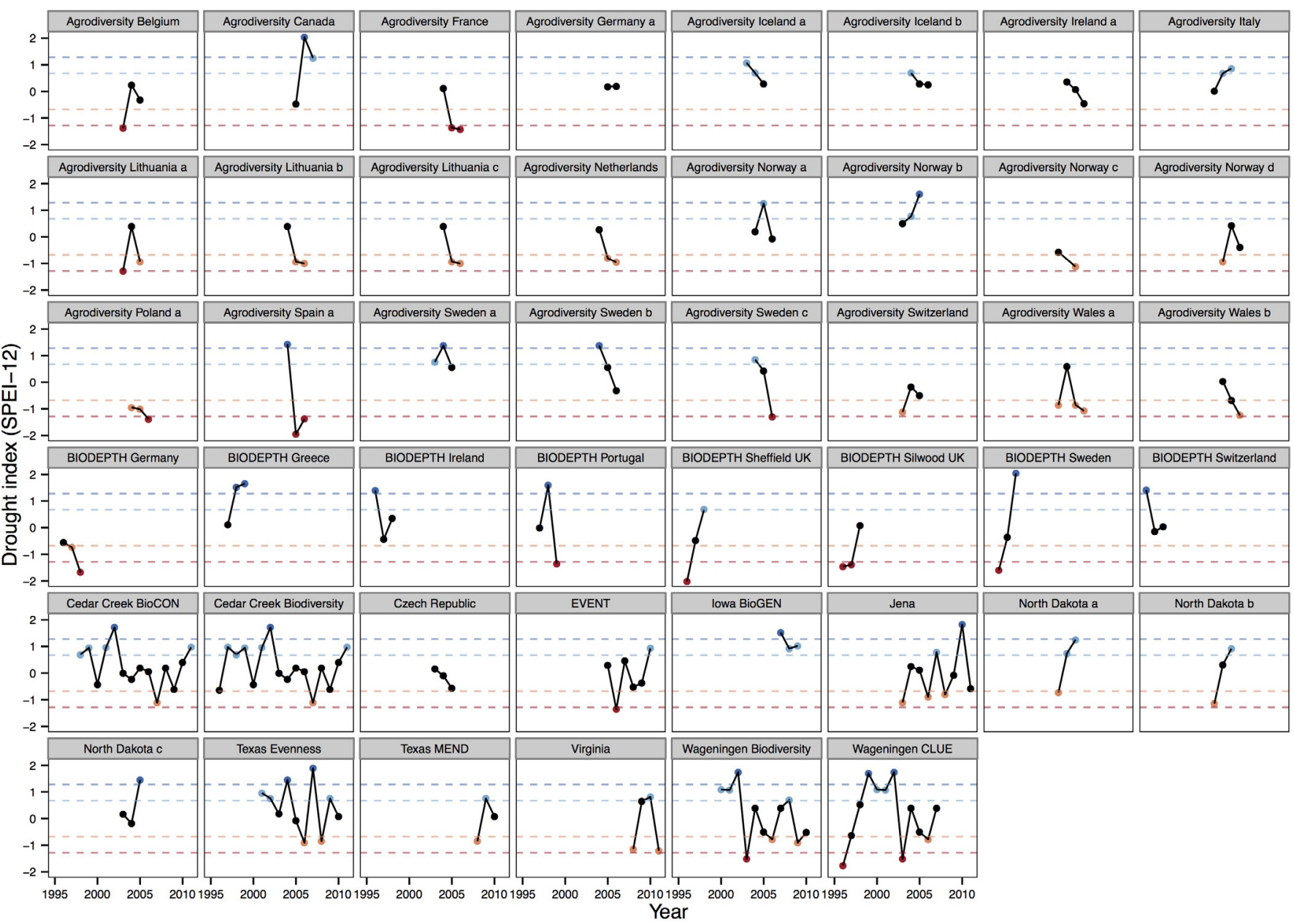

Extended Data Figure $3 \mid$ Classification of extreme dry, moderate dry, normal, moderate wet, and extreme wet years for each year of the 46 experiments. The 12-month version of the SPEI is shown, where positive values indicate wetter than normal water balances (precipitation minus potential evapotranspiration) during the 12 -month time interval preceding and including the month of peak biomass harvest. For example, if peak biomass was harvested in September, then SPEI-12 accounts for the water balance from the previous October to September. Drought index values are based on monthby-month variations in climate over the past century (January 1901 to
December 2011), based on monthly means of measurements made at more than 4,000 weather stations worldwide, and provided on 0.5 degree $\times 0.5$ degree grids globally. Dashed lines show cutoffs for 1 in $4( \pm 0.67)$ or 1 in 10 $( \pm 1.28)$ year events. Seven experiments that included only normal years (Agrodiversity Germany a, Agrodiversity Ireland a, Czech Republic) or that did not include any normal years (Agrodiversity Poland a, Agrodiversity Spain a, Iowa BioGEN, North Dakota a) were excluded from subsequent analyses because it was not possible to compare perturbed with normal productivity levels for these studies. 


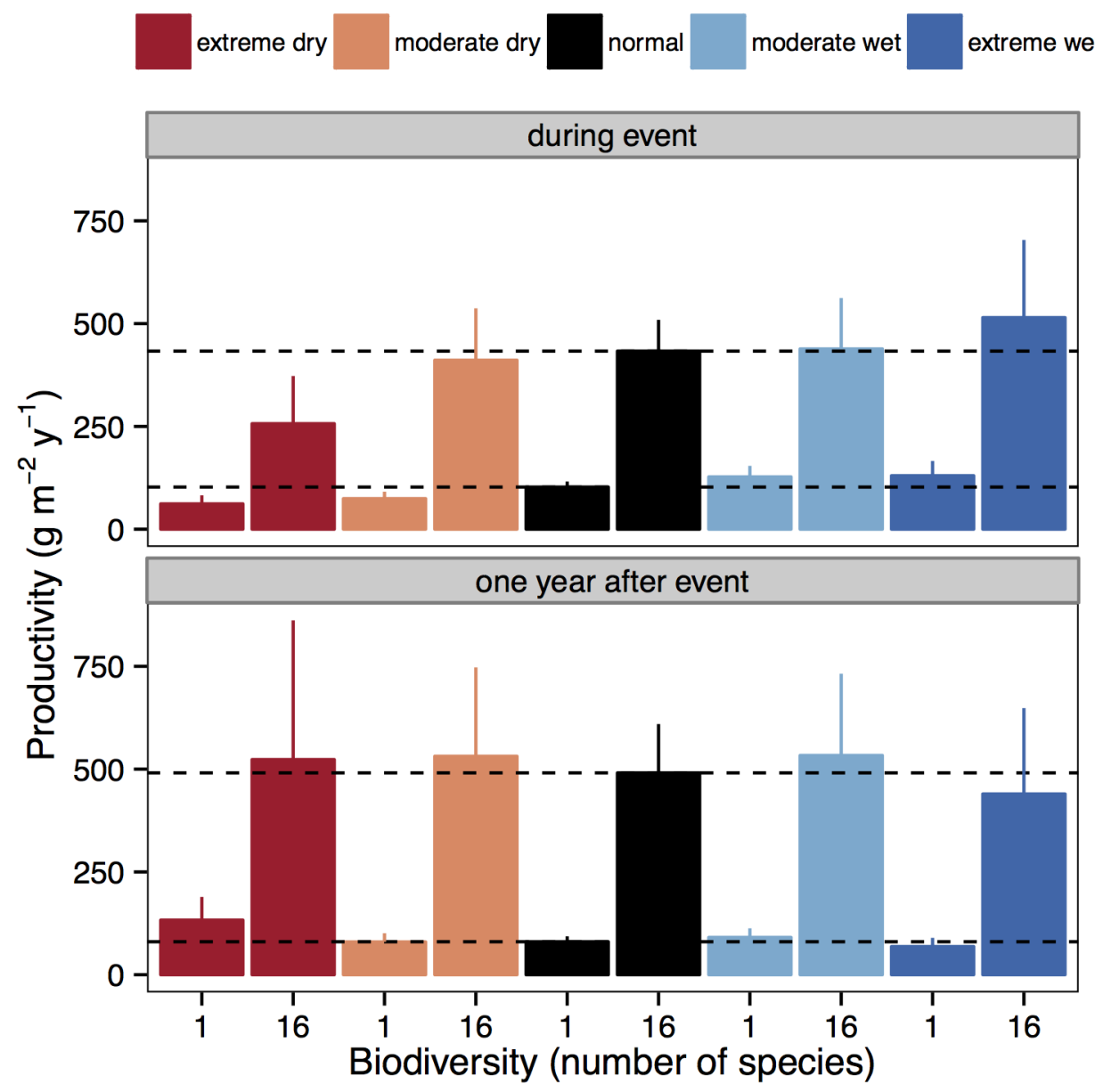

Extended Data Figure $4 \mid$ Productivity during and after both climate events and normal years for monocultures and mixtures of 16 species. Values shown are predicted means and $95 \%$ confidence intervals from the mixedeffects model. Productivity tends to be decreased during dry events and increased during wet events. This trend is reversed during the year after climate events. This pattern of overshooting normal levels of productivity during recovery 1 year after climate events is consistent with damped oscillations, rather than monotonic recovery (Extended Data Fig. 1). Relatively high productivity after extreme droughts could be due to increased nutrient availability and/or decreased abundance of herbivores as a result of reduced plant productivity during the drought. This might be especially true for lowdiversity communities, which have the lowest productivity during drought, possibly explaining why biodiversity increases resilience after extremely dry years (Fig. 1c). Similarly, relatively low productivity after extremely wet years might be due to decreased nutrient availability and/or increased abundance of enemies as a result of increased plant productivity during the wet event. This might be especially true for high-diversity communities, which have the highest productivity during wet years, possibly explaining why biodiversity decreases resilience after extremely wet years (Fig. 1c). Dashed horizontal lines show normal productivity levels. 
$\rightarrow$ extreme dry $\rightarrow$ moderate dry $\rightarrow$ normal $\rightarrow$ moderate wet $\rightarrow$ extreme wet

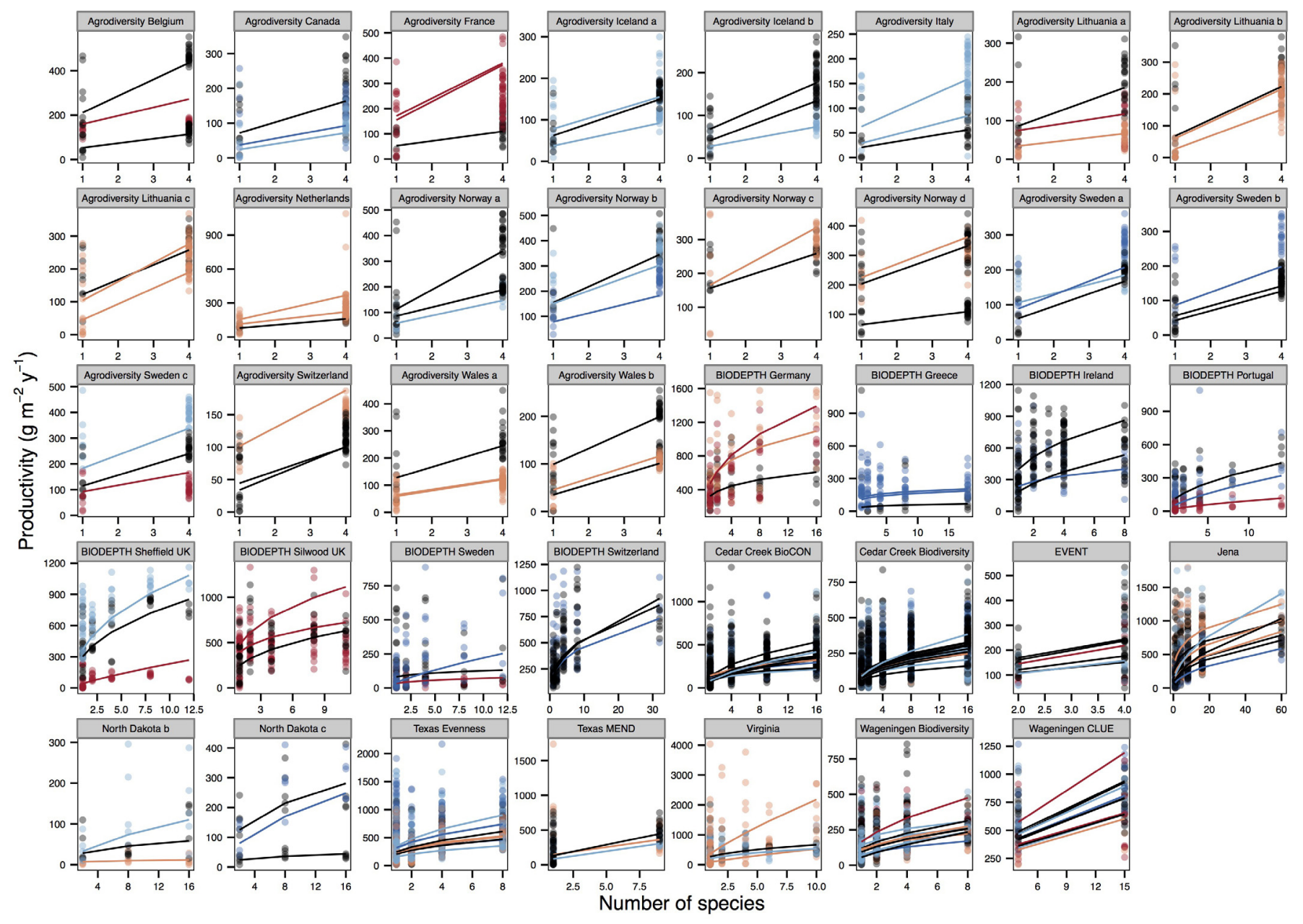

Extended Data Figure $5 \mid$ Biodiversity-productivity relationships for each year of each study, including normal years and climate events. Points are plotlevel values and lines are mixed-model fits (Fig. 3). 


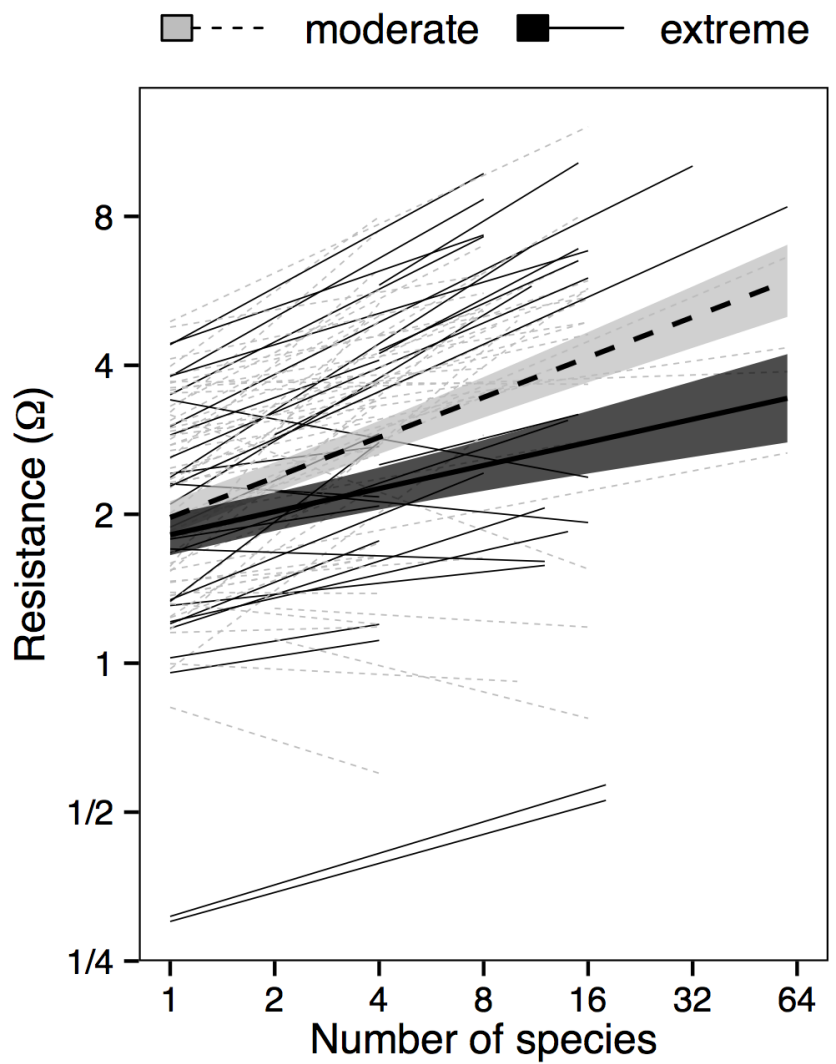

Extended Data Figure 6 A marginally significant interaction between biodiversity and intensity (moderate or extreme). Table 1 indicates that productivity was marginally more resistant to moderate than to extreme climate events, especially at high biodiversity. All other interactions were non-significant $(P>0.10)$. Axes are logarithmic. 


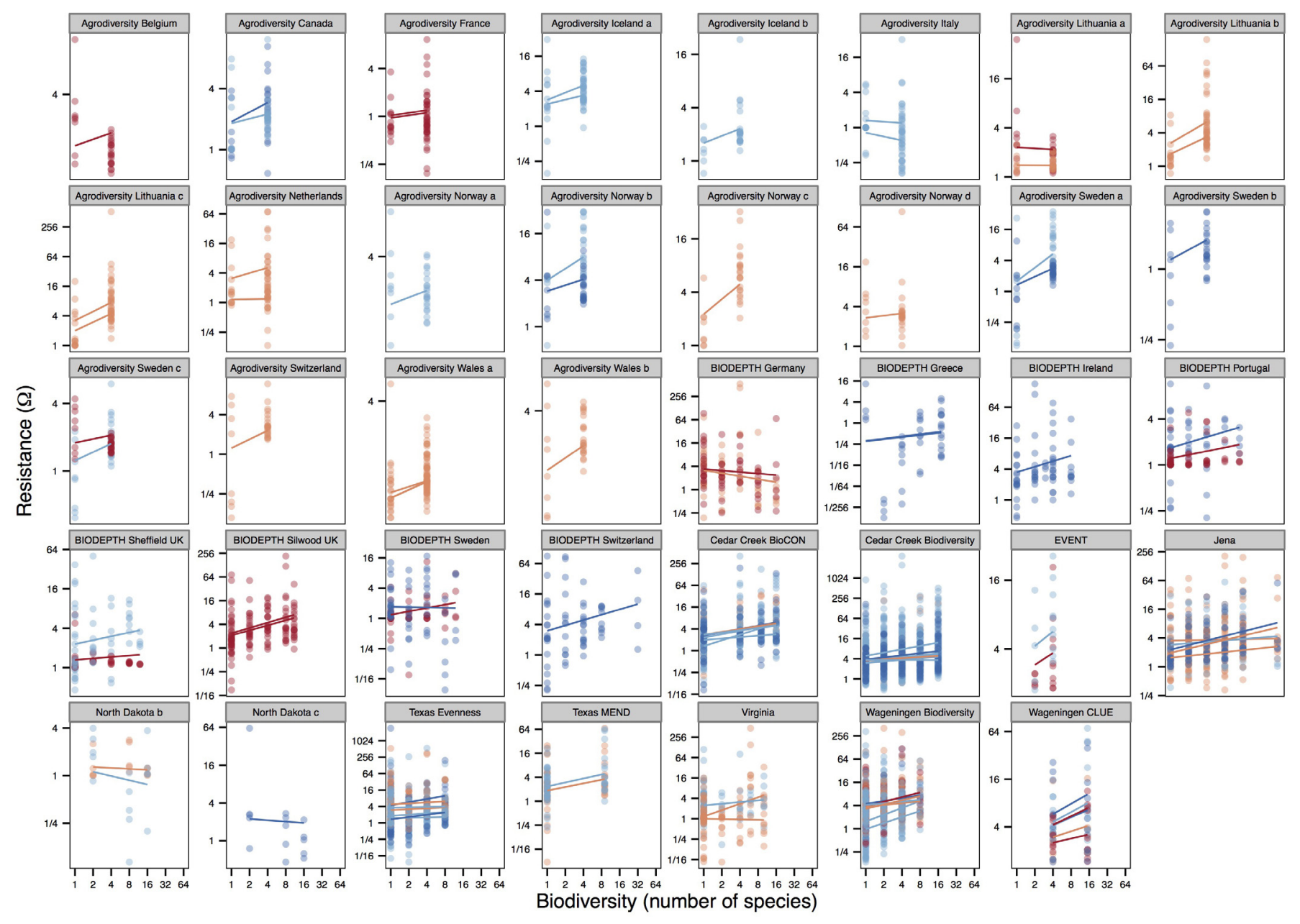

Extended Data Figure $7 \mid$ Biodiversity effects on the resistance of productivity to climate extremes. Shown for each study for which there were observations of productivity during both normal $\left(\overline{Y_{\mathrm{n}}}\right)$ and climate event $\left(Y_{\mathrm{e}}\right)$

years (Extended Data Fig. 3). Points are plot-level values and lines are mixedmodel fits (Fig. 1b). Axes are logarithmic. 
$\rightarrow$ extreme dry $\rightarrow$ dry $\rightarrow$ wet $\rightarrow$ extreme wet
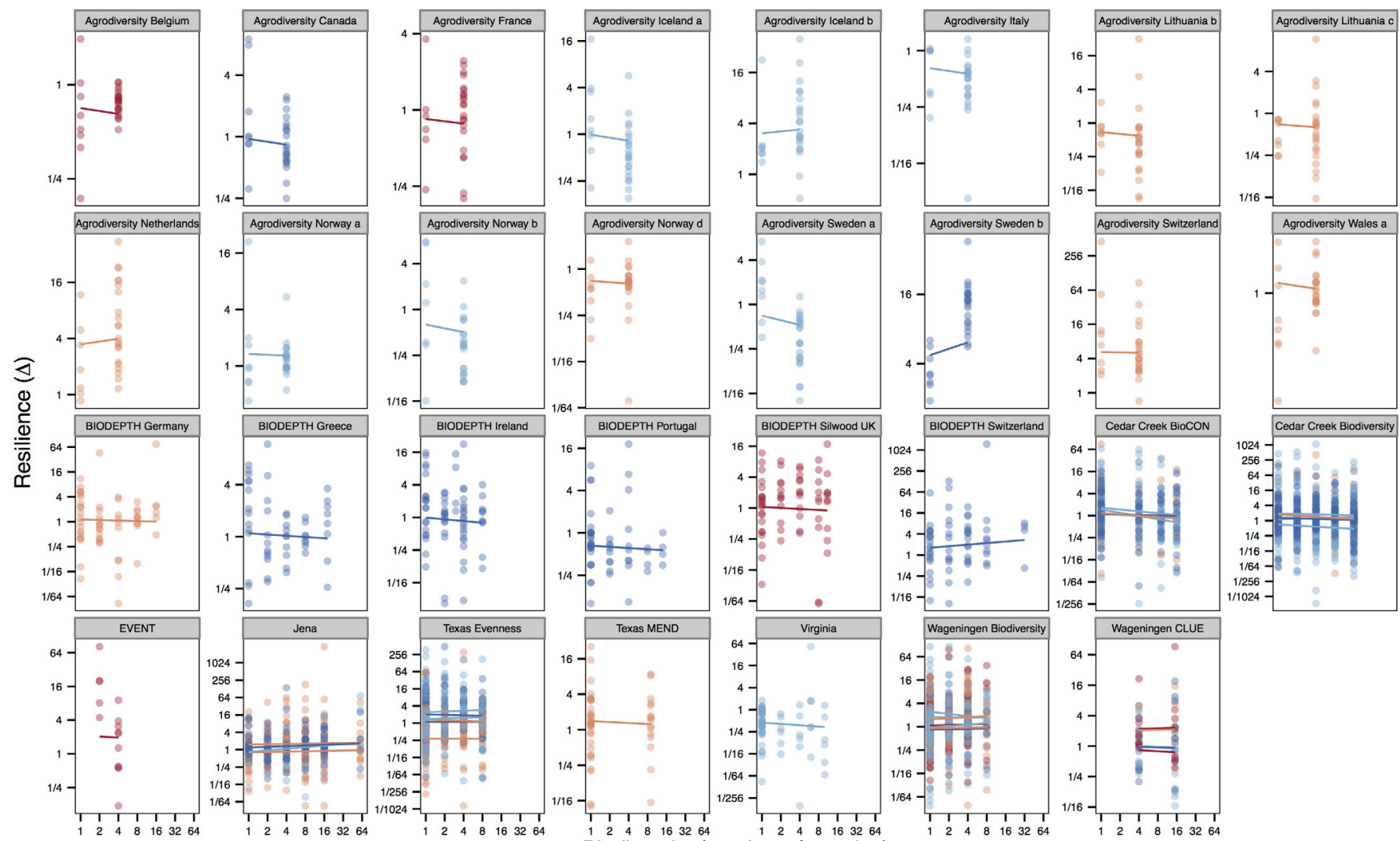

Extended Data Figure $8 \mid$ Biodiversity effects on the resilience of Biodiversity (number of species)

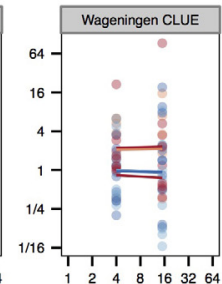

productivity to climate extremes. Shown for each study for which there were observations during normal $\left(\overline{Y_{\mathrm{n}}}\right)$, climate event $\left(Y_{\mathrm{e}}\right)$, and post-climate event $\left(Y_{\mathrm{e}+1}\right)$ years. Quantifying resilience requires more information (that is, $\left.Y_{\mathrm{e}+1}\right)$ than quantifying resistance, thus we were unable to quantify resilience for eight of the studies shown in Extended Data Fig. 7. Specifically, we were

unable to quantify resilience for studies where the only climate event occurred during the last year of the study (Extended Data Fig. 3) because in this case $Y_{\mathrm{e}+1}$ is unknown, and for studies where the only normal year was also the only post-event year (Extended Data Fig. 3) because in this case $\overline{Y_{\mathrm{n}}}=Y_{\mathrm{e}+1}$ and resilience is undefined. Points are plot-level values and lines are mixed-model fits (Fig. 1c). Axes are logarithmic. 


\section{RESEARCH LETTER}

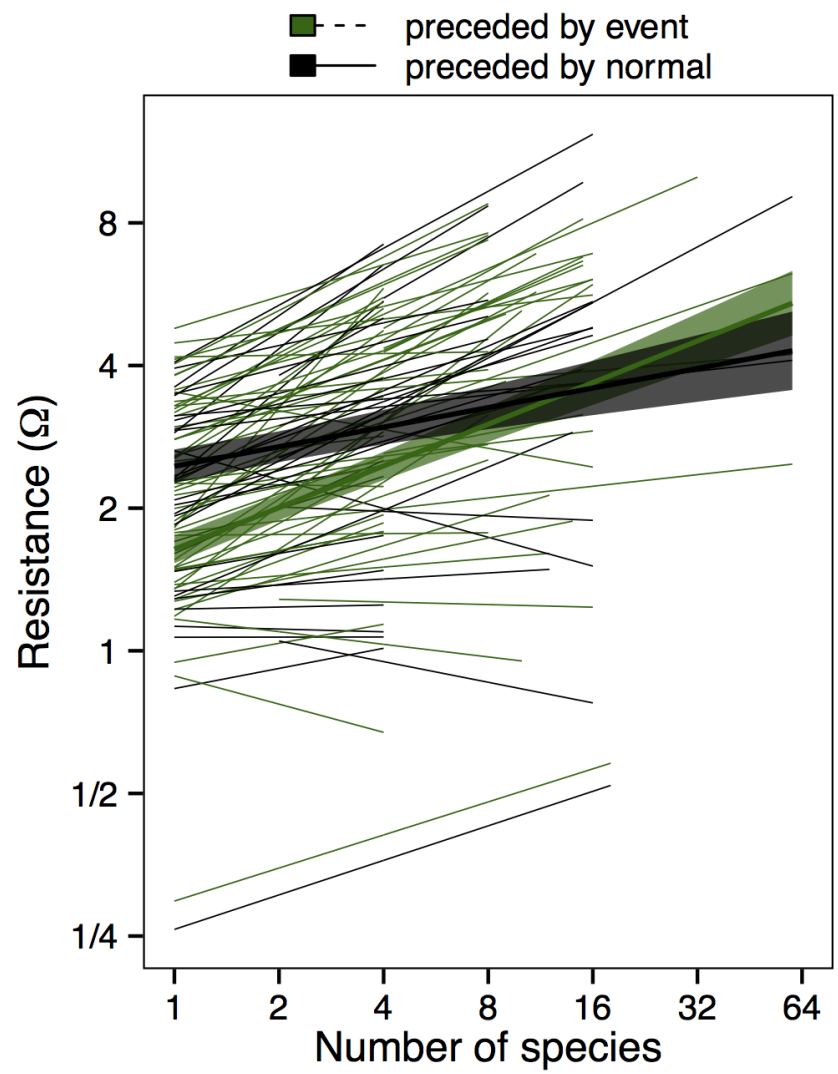

Extended Data Figure $9 \mid$ Biodiversity effects on the resistance of productivity to climate events that were preceded either by a climate event (green lines) or by a normal year (black lines). The significant interaction shown here indicates that biodiversity increased resistance more during climate events preceded by years with climate events than during climate events preceded by normal years $\left(F_{1,64.8}=7.21, P<0.01\right)$. Axes are logarithmic. The sequence of climate events at each site is shown in Extended Data Fig. 3. 
Extended Data Table 1 | Study details

\begin{tabular}{|c|c|c|c|c|c|}
\hline Study & Years & $\begin{array}{l}\text { \# of } \\
\text { years }\end{array}$ & $\begin{array}{l}\text { Month } \\
\text { of peak } \\
\text { biomass } \\
\text { harvest }\end{array}$ & $\begin{array}{l}\text { \# of } \\
\text { plots }\end{array}$ & $\begin{array}{l}\text { Levels of } \\
\text { species } \\
\text { richness }\end{array}$ \\
\hline Agrodiversity Belgium & $2003-2005$ & 3 & 11 & 30 & 1,4 \\
\hline Agrodiversity Canada & $2005-2007$ & 3 & 8 & 30 & 1,4 \\
\hline Agrodiversity France & 2004-2006 & 3 & 10 & 30 & 1,4 \\
\hline Agrodiversity Germany a & $2005-2006$ & 2 & 10 & 30 & 1,4 \\
\hline Agrodiversity Iceland a & 2003-2005 & 3 & 8 & 30 & 1,4 \\
\hline Agrodiversity Iceland b & 2004-2006 & 3 & 8 & 30 & 1,4 \\
\hline Agrodiversity Ireland a & 2004-2006 & 3 & 11 & 29 & 1,4 \\
\hline Agrodiversity Italy & 2003-2005 & 3 & 12 & 30 & 1,4 \\
\hline Agrodiversity Lithuania a & $2003-2005$ & 3 & 10 & 30 & 1,4 \\
\hline Agrodiversity Lithuania b & $2004-2006$ & 3 & 10 & 30 & 1,4 \\
\hline Agrodiversity Lithuania c & 2004-2006 & 3 & 10 & 30 & 1,4 \\
\hline Agrodiversity Netherlands & 2004-2006 & 3 & 10 & 30 & 1,4 \\
\hline Agrodiversity Norway a & $2004-2006$ & 3 & 8 & 30 & 1,4 \\
\hline Agrodiversity Norway b & 2003-2005 & 3 & 9 & 30 & 1,4 \\
\hline Agrodiversity Norway c & 2003-2005 & 2 & 10 & 30 & 1,4 \\
\hline Agrodiversity Norway d & 2004-2006 & 3 & 8 & 30 & 1,4 \\
\hline Agrodiversity Poland a & $2004-2006$ & 3 & 10 & 30 & 1,4 \\
\hline Agrodiversity Spain a & 2004-2006 & 3 & 7 & 30 & 1,4 \\
\hline Agrodiversity Sweden a & $2003-2005$ & 3 & 9 & 30 & 1,4 \\
\hline Agrodiversity Sweden b & 2004-2006 & 3 & 9 & 30 & 1,4 \\
\hline Agrodiversity Sweden c & 2004-2006 & 3 & 9 & 30 & 1,4 \\
\hline Agrodiversity Switzerland & $2003-2005$ & 3 & 10 & 30 & 1,4 \\
\hline Agrodiversity Wales a & $2003-2006$ & 4 & 10 & 30 & 1,4 \\
\hline Agrodiversity Wales b & 2004-2006 & 3 & 11 & 30 & 1,4 \\
\hline BIODEPTH Germany & $1996-1998$ & 3 & 8 & 60 & $1,2,4,8,16$ \\
\hline BIODEPTH Greece & $1997-1999$ & 3 & 5 & 52 & $1,2,4,8,18$ \\
\hline BIODEPTH Ireland & 1996-1998 & 3 & 8 & 70 & $1,2,3,4,8$ \\
\hline BIODEPTH Portugal & $1997-1999$ & 3 & 5 & 56 & $1,2,4,8,14$ \\
\hline BIODEPTH Sheffield UK & 1996-1998 & 3 & 9 & 54 & $1,2,4,8,12$ \\
\hline BIODEPTH Silwood UK & 1996-1998 & 3 & 9 & 66 & $1,2,4,8,11$ \\
\hline BIODEPTH Sweden & 1996-1998 & 3 & 8 & 58 & $1,2,4,8,12$ \\
\hline BIODEPTH Switzerland & $1995-1997$ & 3 & 8 & 64 & $1,2,4,8,32$ \\
\hline Cedar Creek BioCON & 1998-2011 & 14 & 8 & 74 & $1,4,9,16$ \\
\hline Cedar Creek Biodiversity & $1996-2011$ & 16 & 8 & 168 & $1,2,4,8,16$ \\
\hline Czech Republic & 2003-2005 & 3 & 6 & 96 & $1,3,6,12$ \\
\hline EVENT & $2005-2010$ & 6 & 9 & 15 & 2,4 \\
\hline lowa BioGEN & 2007-2009 & 3 & 8 & 64 & 1,4 \\
\hline Jena & $2003-2011$ & 9 & 9 & 82 & $1,2,4,8,16,60$ \\
\hline North Dakota a & 2003-2005 & 3 & 8 & 15 & $2,8,16$ \\
\hline North Dakota b & $2003-2005$ & 3 & 8 & 15 & $2,8,16$ \\
\hline North Dakota c & 2003-2005 & 3 & 8 & 15 & $2,8,16$ \\
\hline Texas Evenness & $2001-2010$ & 10 & 10 & 75 & $1,2,4,8$ \\
\hline Texas MEND & $2008-2010$ & 3 & 10 & 52 & 1,9 \\
\hline Virginia & $2008-2011$ & 4 & 8 & 64 & $1,2,4,6,10$ \\
\hline Wageningen Biodiversity & $2000-2010$ & 11 & 8 & 102 & $1,2,4,8$ \\
\hline Wageningen CLUE & 1996-2007 & 12 & 8 & 10 & 4,15 \\
\hline
\end{tabular}

